\title{
Four cases of Raoultella planticola conjunctivitis
}

\begin{abstract}
Aims This brief report of four cases of conjunctivitis caused by Raoultella planticola provides a description of possibly the first documented cases of this eye infection. Methods The laboratory database and medical records were used to trace all the $R$. planticola-positive conjunctival swabs obtained in our institution. Four cases were identified and available relevant information was obtained.

Results This organism causes a non-specific purulent conjunctivitis that seems to have a benign course and tends to be responsive to a topical fluoroquinolone.

Conclusions The possibility of atypical organisms must be considered when managing infective conjunctivitis. Conjunctival swabs should be obtained and topical treatment switched when initial empirical therapy fails. Eye (2016) 30, 632-634; doi:10.1038/eye.2015.260; published online 8 January 2016
\end{abstract}

\section{${ }^{1}$ Ophthalmology \\ Department, Mater Dei Hospital, Msida, Malta \\ 2Pathology Department, Mater Dei Hospital, Msida, Malta}

Correspondence: J Vassallo, Ophthalmology Department, Mater Dei Hospital, Msida, MSD 2090, Malta

Tel: +356 25450000;

Fax: +356 25454154

E-mail: jamesvassallo2000@ yahoo.com

Received: 11 July 2015 Accepted in revised form: 29 October 2015

Published online:

8 January 2016

\section{Introduction}

Raoultella planticola is a Gram-negative, non-motile, oxidase-negative, catalase-positive, capsulated, facultative anaerobic rod in the family Enterobacteriacae. ${ }^{1}$ It is found in aquatic environments, soil, and fish. It was also isolated from various clinical specimens. ${ }^{2}$ We hereby report four cases of $R$. planticola conjunctivitis.

\section{Case reports}

In these cases, eye swabs were submitted to the laboratory for bacterial culture. The swabs were inoculated onto two blood agar plates anaerobic conditions) and a MacConkey agar plate (incubated under aerobic conditions). All plates were incubated at $37^{\circ} \mathrm{C}$ for $18-24 \mathrm{~h}$. Mucoid bacterial colonies proliferated in all these plates and all were oxidase-negative, (one incubated with extra $\mathrm{CO}_{2}$ and one under fermentative, Gram-negative rods. Bacterial identification was carried out with the automated VITEK-2 compact system by using GN-ID cards (bioMérieux, Marcy l'Etoile, France; 95\% probability) and antibiotic susceptibility results were obtained using a VITEK-2 AST card (bioMérieux) according to ECAST methods.

\section{Case 1}

A 88-year-old female with no significant past medical history or susceptibility for infection. She stays mostly indoors in a clean environment and reports no contact with animals or soil. Her left eye was enucleated for endophthalmitis secondary to a corneal leak in a blind eye. An initial conjunctival swab at the time had revealed Proteus mirabilis. The eye socket eventually healed well and since then she had been fitted with a conformer that was cleaned regularly with saline. Fourteen months following the enucleation, she presented with a 1-week history of yellowish discharge, sticky eye, and redness. A conjunctival swab was taken and she was started on empirical treatment with topical $0.3 \%$ gentamicin drops qds. The swab yielded $R$. planticola with a 93\% probability and there were no other co-cultured bacteria (see Table 1 for sensitivities). After 8 days she failed to respond satisfactorily to gentamicin and she was switched to $0.3 \%$ ciprofloxacin drops tds with resolution of symptoms after 2 weeks; the antibiotic drops were continued for 3 weeks in total and the patient remained asymptomatic.

A retrospective search of the local microbiology laboratory database revealed three further cases of swabs positive for R. planticola. The percentage probability of $R$. planticola identification for these cases could not be retrieved. The information that could be gathered about these cases follows.

\section{Case 2}

A 71-year-old male who presented with unilateral purulent discharge, pain, pruritus, 
Table 1 Antibiotic sensitivities

\begin{tabular}{lcccc}
\hline & $\begin{array}{c}\text { Case 1 } \\
\text { April } \\
\end{array}$ & $\begin{array}{c}\text { Case 2 } \\
\text { September } \\
2015\end{array}$ & $\begin{array}{c}\text { Case 3 } \\
\text { July } \\
2012\end{array}$ & $\begin{array}{c}\text { Case 4 } \\
\text { March } \\
2011\end{array}$ \\
\hline Ampicillin & $\mathrm{R}$ & $\mathrm{R}$ & $\mathrm{R}$ & $\mathrm{R}$ \\
Co-amoxiclav & $\mathrm{S}$ & $\mathrm{S}$ & $\mathrm{S}$ & $\mathrm{S}$ \\
Piperacillin & $\mathrm{S}$ & $\mathrm{R}$ & $\mathrm{R}$ & $\mathrm{R}$ \\
Pip/Tazobactam & $\mathrm{S}$ & $\mathrm{S}$ & $\mathrm{S}$ & $\mathrm{S}$ \\
Cefoxitin & $\mathrm{n} / \mathrm{a}$ & $\mathrm{n} / \mathrm{a}$ & $\mathrm{S}$ & $\mathrm{S}$ \\
Ceftazidime & $\mathrm{S}$ & $\mathrm{S}$ & $\mathrm{S}$ & $\mathrm{S}$ \\
Imipenem & $\mathrm{S}$ & $\mathrm{S}$ & $\mathrm{S}$ & $\mathrm{S}$ \\
Gentamicin & $\mathrm{S}$ & $\mathrm{S}$ & $\mathrm{S}$ & $\mathrm{S}$ \\
Ciprofloxacin & $\mathrm{S}$ & $\mathrm{S}$ & $\mathrm{S}$ & $\mathrm{S}$ \\
Tetracycline & $\mathrm{n} / \mathrm{a}$ & $\mathrm{n} / \mathrm{a}$ & $\mathrm{S}$ & $\mathrm{S}$ \\
Trimeth Sulfa & $\mathrm{S}$ & $\mathrm{S}$ & $\mathrm{S}$ & $\mathrm{S}$ \\
Meropenem & $\mathrm{S}$ & $\mathrm{n} / \mathrm{a}$ & $\mathrm{n} / \mathrm{a}$ & $\mathrm{n} / \mathrm{a}$ \\
Fosfomycin & $\mathrm{R}$ & $\mathrm{n} / \mathrm{a}$ & $\mathrm{n} / \mathrm{a}$ & $\mathrm{n} / \mathrm{a}$ \\
\hline
\end{tabular}

and blurred vision after he had scratched that eye with a twig. He had already been swabbed 2 weeks prior and 3 different bacteria had been cultivated. Topical gentamicin therapy was ongoing when a second swab was taken and yielded $R$. planticola.

\section{Case 3}

A 15-year-old female in whom $R$. planticola was co-cultured with three other bacteria; no further information is available.

\section{Case 4}

A 69-year-old female who presented for cataract surgery, which was postponed due to signs of infection. A swab yielding $R$. planticola was obtained. She was not on antibiotics before the conjunctival swabbing. She was successfully treated with a week of topical drops of unknown identity, and was successfully operated after a few weeks without complications. However, she had recurrent conjunctivitis-like episodes every few months that year, requiring multiple courses of topical therapy. This case dates back to March 2011 and to our knowledge it may represent the first documented case of $R$. planticola conjunctivitis.

\section{Discussion}

R. planticola was formerly considered to be a member of environmental Klebsiella until the late 1990s. These included Klebsiella terrigena, K. ornithinolytica, K. planticola, and K. trevisanii. In 1986, the last two organisms were placed in the same species $K$. planticola because of similar phenotypic characteristics and extensive DNA sequence homology. ${ }^{3}$ In 2001, K. planticola was transferred to the new genus Raoultella on the basis of $16 \mathrm{~S}$ rRNA and rpoB sequences and the name $R$. planticola was proposed to replace K. planticola. ${ }^{1}$

The first documented case of Raoultella conjunctivitis was reported in 2014 by Zuberbuhler et al. ${ }^{4}$ Hence, this case series may represent the earliest reported cases so far. Other reported cases of Raoultella infections affected extraocular sites. ${ }^{5}$

Microbiological identification in our lab was carried out with the VITEK-2 system, which has been shown to have a high identification rate for Gram-negative rods. ${ }^{6}$ VITEK-2 can differentiate between $R$. planticola and $R$. ornithinolytica with a probability of good identification at $93-99 \%$. Correct identification of organisms allows an accurate diagnosis and provides a true picture of the local microbiological trends.

In patients 1 and 2, it is noted that despite the organism being sensitive to gentamicin, the infection failed to respond adequately to it. Hence, it is proposed that a fluoroquinolone may be a first-line approach for management of Raoultella conjunctivitis, as all four swabs in this series revealed sensitivity to ciprofloxacin. In the case by Zuberbuhler et al, ${ }^{4}$ there was resolution of the infection with chloramphenicol, which may thus be an alternative to fluoroquinolones.

Even though this organism is an environmental organism, only in patient 2 was contact with vegetable matter apparent in the history. Hence, lack of environmental exposure does not exclude the possibility of infection by this bacterium. Other possible sources of $R$. planticola include food and antimicrobial liquid soap, the latter having particular significance in the healthcare setting given the emphasis on hand hygiene. ${ }^{7,8}$

To conclude, this report possibly describes the earliest documented cases of $R$. planticola conjunctivitis and proposes fluoroquinolones as first-line therapy in these cases. Conjunctival swabs should be taken whenever possible in order to detect atypical organisms and a history of contact with soil or fish should prompt the possibility of $R$. planticola conjunctivitis.

\section{Summary}

What was known before

- Bacterial conjunctitivitis is initially treated empirically based on local sensitivities.

- Conjunctival swabbing can provide useful information in recalcitrant cases.

\section{What this study adds}

- Raoultella conjunctivitis is rare and seems to be sensitive to topical fluoroquinolones.

- This organism has to be considered even in cases with no contact with soil or fish. 


\section{Conflict of interest}

The authors declare no conflict of interest.

\section{References}

1 Drancourt M, Bollet C, Carta A, Rousselier P. Phylogenetic analyses of Klebsiella species delineate Klebsiella and Raoultella gen. nov., with description of Raoultella ornithinolytica comb. nov., Raoultella terrigena comb. nov. and Raoultella planticola comb. nov. Int J Syst Evol Microbiol 2001; 51(Pt 3): 925-932.

2 Teo I, Wild J, Ray S, Chadwick D. A rare case of cholecystitis caused by Raoultella planticola. Case Rep Med 2012; 2012: 1-3.

3 Gavini F, Izard D, Grimont PAD, Beji A, Ageron E, Leclerc H. Priority of Klebsiella planticola Bagley, Seidler, and Brenner 1982 over Klebsiella trevisani Ferragut, Izard, Gavini, Kersters, DeLey, and Leclerc 1983. Int J Syst Bacteriol 1986; 36(3): 486.
4 Zuberbuhler B, Abedin A, Roudsari A. A novel case of chronic conjunctivitis in a 58 -year-old woman caused by Raoultella. Infection 2014; 42(5): 927-929.

5 Salmaggi C, Ancona F, Olivetti J, Pagliula G, Ramirez GA. Raoultella planticola-associated cholangitis and sepsis: a case report and literature review. QJM 2014; 107(11): 911-913.

6 Renaud FN, Bergeron E, Tigaud S, Fuhrmann C, Gravagna B, Freney J. Evaluation of the new Vitek 2 GN card for the identification of gram-negative bacilli frequently encountered in clinical laboratories. Eur J Clin Microbiol Infect Dis 2005; 24 (10): 671-676.

7 Lam PW, Salit IE. Raoutella planticola bacteraemia following consumption of seafood. Can J Infect Dis Med Microbiol 2014; 25(4): e83-e84.

8 Momeni SS, Tomlin N, Ruby JD. Isolation of Raoultella planticola from refillable antimicrobial liquid soap dispensers in a dental setting. JADA 2015; 146(4): 241-245. 